\title{
ARTICLE Cervical spine epidural abscess: a single center analytical comparison to the literature
}

\author{
Faris Shweikeh ${ }^{1,2}$, Mohammed Hussain ${ }^{3}$, Ajleeta Sangtani ${ }^{1}$, Husam Issa ${ }^{4}$, Asif Bashir ${ }^{3}$, J Patrick Johnson ${ }^{2}$ and Georges Z Markarian ${ }^{1}$
}

STUDY DESIGN: Retrospective review of patient charts.

OBJECTIVES: Cervical spine epidural abscess (CSEA) is uncommon. In this study, characteristics of CSEA patients are described through an institutional analysis and literature review.

SETTING: University-affiliated city hospital.

METHODS: The electronic medical record was searched from 01/2001 to 01/2012. Data on presentation, comorbidities, diagnostic modalities, pathogens, treatments, and neurological recovery were collected.

RESULTS: Sixteen patients were identified with a mean age of 57.9 years (33-83). Nine were females. Common symptoms were neck/back pain (62.5\%), neurological deficits (62.5\%), and fever (31.3\%). Comorbidities included cardiovascular disease (56.3\%), renal disease (37.5\%), and diabetes mellitus (37.5\%). Lower levels were more likely afflicted (C5-C7). Microorganisms were commonly Staphylococcus and Streptococcus (68.8\%). Eight (50.0\%) received surgery (anterior [87.5\%] and posterior [12.5\%] cervical fusion and corpectomy [37.5\%]) plus antibiotics and 8 (50.0\%) were treated with antibiotics only. Patients with less comorbidities were more likely to receive surgery; more comorbidities were associated with a poor prognosis. Eight patients (50\%) made full neurological recovery, 2 (12.5\%) had minimal recovery, 2 died, and 4 (25\%) were lost to follow-up (including 2 sent to a skilled nursing facility).

CONCLUSIONS: Cervical SEA can be problematic. The vast majority do not present classically and treatment does vary. It occurs more frequently in the lower cervical levels. Though antibiotics alone may suffice, surgery is frequently employed and a multitude of techniques are at the utility of the spine surgeon. Cardiovascular comorbidities are associated with a poorer outcome. In order to improve prognosis, management considerations should include both patient factors and multidisciplinary efforts.

Spinal Cord Series and Cases (2017) 3, 17036; doi:10.1038/scsandc.2017.36; published online 6 July 2017

\section{INTRODUCTION}

Spinal epidural abscess (SEA) is a rare entity, accounting for $\sim 2$ to 25 admissions per 100000 hospital admissions. ${ }^{1}$ The infection is most commonly caused by Staphylococcus aureus, but can be caused by a range of other bacteria or fungi. ${ }^{2}$ Many risk factors are associated with SEA, including diabetes mellitus, drug and alcohol abuse, liver and renal failure, and invasive procedures. ${ }^{3-6}$ The infectious process typically occurs in the thoracic or lumbar region, though cervical SEA (CSEA) does occur. ${ }^{4,7}$ Estimates on the frequency of abscesses in the cervical region are in the vicinity of $\sim 14 \%$ of all SEA. ${ }^{8}$

The exact pathophysiology of CSEA is unknown, but the most prominent hypothesis is that hematogenous or lymphatic channels cause spread from remote locations (Figure 1). $)^{5,9}$ Anatomically, formation of an infectious collection within the spinal canal presents as an emergency to the clinician, as the small area surrounding the thecal sac limits the progression of any adjacent disease process such as an abscess. ${ }^{10}$ At the condition's highpoint, there is compression of nervous structures and the cord itself resulting in neurological sequelae. The ambiguity of symptoms often causes long delays in diagnosis, challenging clinicians further. ${ }^{9}$
However, the literature is scarce in regards to CSEA, elucidated mostly in case reports and a few case series. Moreover, recent evidence indicates that the SEA condition is currently on the rise and perhaps that it is presenting more aggressively. ${ }^{11,12}$ As such, we report our experience with CSEA over an 11-year period and compare our findings with those in the literature.

\section{MATERIALS AND METHODS}

Institutional Review Board authorization was obtained and the electronic medical record at Summa Health System was reviewed for all patients discharged with a diagnosis of spinal epidural abscess from January 2002 to January 2012. After excluding cases that were readmissions and those lacking complete data, we found 106 patients. From this cohort, we identified 16 patients with a SEA localized to the cervical spine. Each of the patient's charts were examined from admission until discharge, gauging for the symptoms and signs of the condition, risk factors, comorbidities, pathogens, mode of diagnosis, type of treatment received and extent of neurological improvement.

Data analysis was performed using Excel (Microsoft Corporation Inc., Redmond, WA, USA) and GraphPad Software (GraphPad Software, La Jolla, CA, USA). Parametric data was analyzed via a $t$-test and Fisher's exact test was applied towards categorical variables. Two-tailed $P$-values $<0.05$ were considered significant.

\footnotetext{
${ }^{1}$ Summa Health System, College of Medicine, Northeast Ohio Medical University, Rootstown, OH, USA; ${ }^{2}$ Department of Neurosurgery, Cedars-Sinai Medical Center,

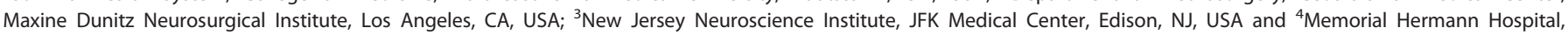
University of Texas Health Science Center, Houston, TX, USA.

Correspondence: F Shweikeh (faris.shweikeh@gmail.com)

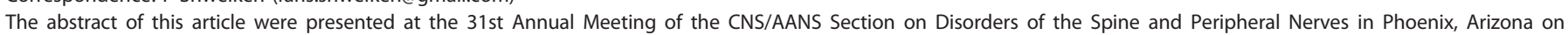
4 March 2015.

Received 20 February 2017; revised 16 May 2017; accepted 20 May 2017
} 


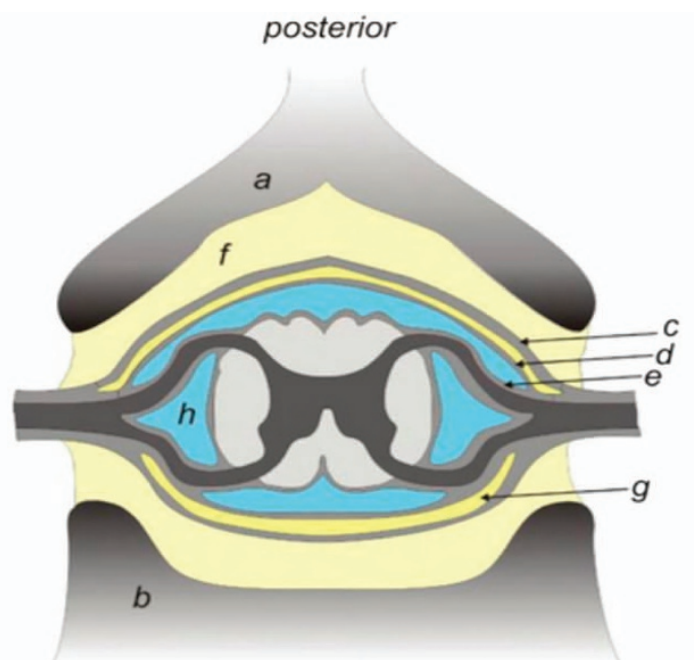

anterior

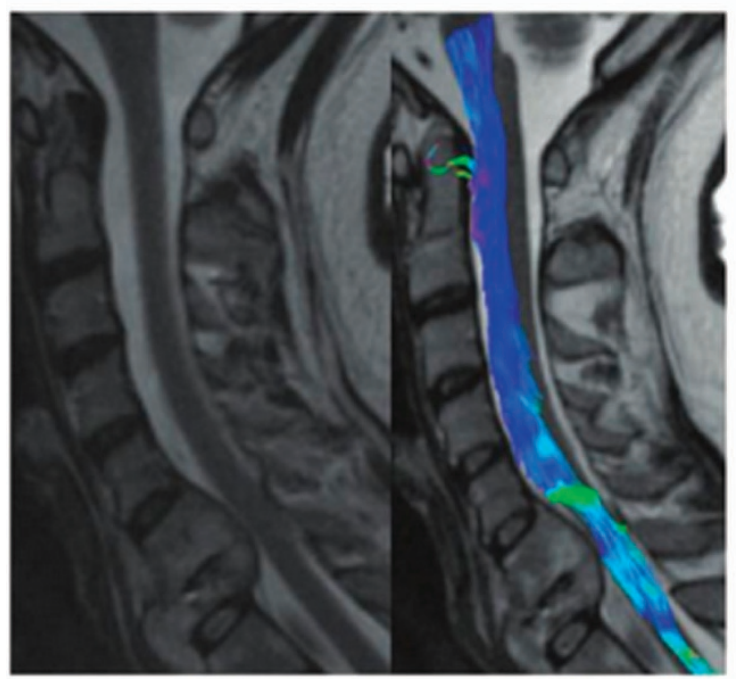

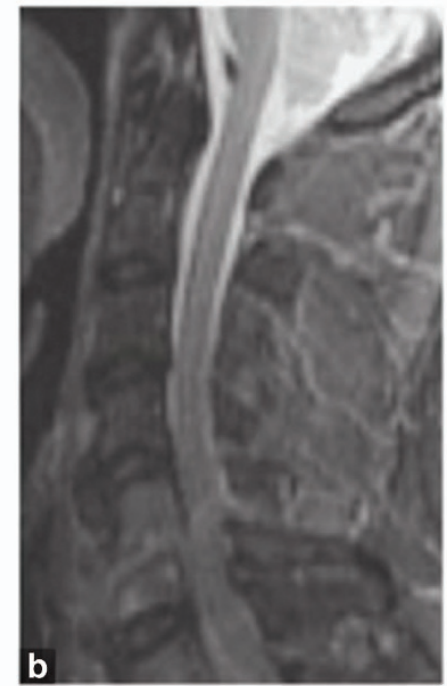
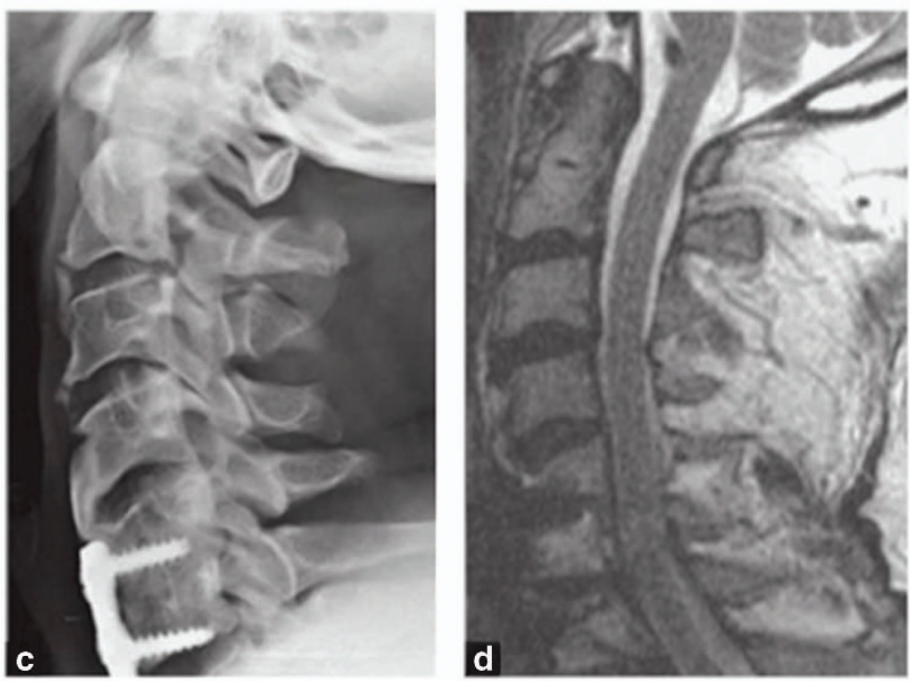

Figure 1. Upper left: Illustration of the structures and spaces surrounding the spinal cord, including the vertebral body, epidural space, subdural space and subarachnoid space. Lower left: T2 sagittal magnetic resonance imaging (MRI) of C6-C7 spondylodiscitis and epidural abscess; diffusion tensor imaging showing the presence of fiber-track continuity at the site of cord compression. Upper and lower right: Patient with spondylodiscitis at C5/C6 (a and b) and results following anterior decompression and fusion (c and d). (Sources: Spinal Infections and Trauma, by S Rajasekaran, Anil K Jain, Ajoy P Shetty, Rishi M Kanna and Infections of the Central Nervous System, by Michael W Scheld, Christina M Marra, Richard J Whitley.)

\section{RESULTS}

Signs, symptoms and origins of infection

Sixteen patients were found with CSEA. There were nine females $(56.25 \%)$ and the average age was 57.9 years. The most common symptoms were neurological, with seven $(43.75 \%)$ patients presenting with paralysis in the extremities and three (18.75\%) presenting with paresthesias. In addition, six (12.5\%) patients presented with neck pain and four $(25 \%)$ with back pain. Other common symptoms included fevers and/or chills (31.25\%) and urinary or bowel symptoms (18.75\%). These results are summarized in Table 1. Most common potential origins of infection were genitourinary in four (25\%), a gastrointestinal focus in three $(18.75 \%)$ and two (12.5\%) of each with the following origins: respiratory, oral and skin.

\section{Level and location}

Patients that had concurrent abscesses at other spinal levels are shown in Table 1, either as an extension beyond the cervical region or as a multifocal infection. Twelve (75\%) patients had SEA only within C1-C7, of which $8(50 \%)$ were ventral, 3 (18.8\%) were dorsal, one (8.3\%) was lateral and four (33.3\%) were in an unspecified location. Two (12.5\%) patients had SEA that included the thoracic region. The abscesses in these patients were located ventrally. Another two patients had multiple SEA in the cervical and lumbar regions, located ventrally. The lower cervical spine was most frequently affected, mostly C5-C7.

\section{Comorbidities and pathogens}

Each of the patients had one or more comorbidities. More than half had vascular disease (56.25\%), six (37.5\%) had diabetes mellitus and five had a history of renal insufficiency or were on dialysis (31.25\%). Other common comorbidities included endocarditis, substance abuse, previous spine surgery, malignancy and chronic inflammatory disease. Figure 2 shows the causative organisms. Methicillin-resistant S. aureus accounted for a multitude of infections (31.25\%), followed by Streptococcus (18.75\%). 
Table 1. Frequency of common presenting symptoms and localization in the current series of CSEA patients

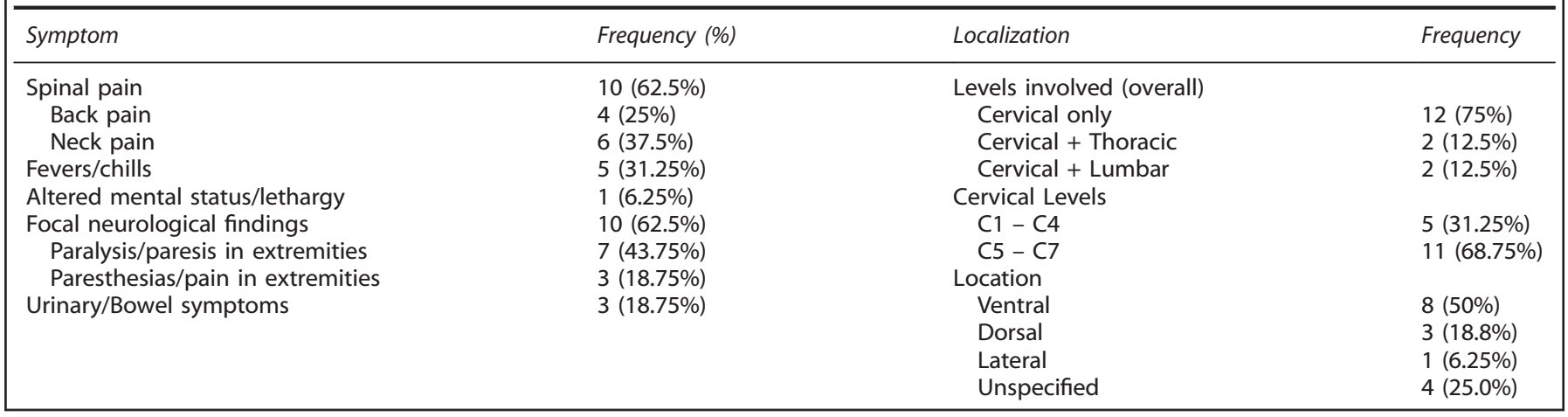

Table 2. Treatments, surgical procedures and outcomes in our series of CSEA patients

\begin{tabular}{lclc}
\hline Treatment & Frequency & Outcome & Frequency \\
\hline $\begin{array}{l}\text { Antibiotics } \\
\text { alone }\end{array}$ & $8(50 \%)$ & $\begin{array}{l}\text { Full recovery; ambulate } \\
\text { independently; no sphincter } \\
\text { disturbance }\end{array}$ & 8 \\
$\begin{array}{l}\text { Antibiotics } \\
\text { +surgery }\end{array}$ & $8(50 \%)$ & $\begin{array}{l}\text { Ambulate with assistance; } \\
\text { possible sphincter } \\
\text { disturbance; paraplegia or } \\
\text { minimal recovery }\end{array}$ & 2 \\
$\begin{array}{l}\text { ACDF } \\
\begin{array}{l}\text { Posterior } \\
\text { decompression } \\
\text { Corpectomy }^{b}\end{array}\end{array}$ & $\begin{array}{l}7(87.5 \%) \\
\text { Expired }\end{array}$ & 2 \\
\hline
\end{tabular}

Abbreviations: ACDF, anterior cervical decompression and fusion; CSEA, cervical spine epidural abscess. ${ }^{\text {aThis }}$ included patients whose data were not available for follow-up results. ${ }^{b}$ Corpectomy in two ACDF and one posterior decompression patient.

Other contributing microorganisms included Methicillin-Sensitive S. aureus and Klebsiella (12.5\% each). In all 16 cases, magnetic resonance imaging was the imaging modality of choice. In addition, in three cases (18.75\%), computerized tomography was also used.

Treatment and outcome

The data regarding treatments offered and chosen surgical procedures is also examined (Table 2). Half the patients received antibiotics alone, with the remaining receiving antibiotics and some form of surgical intervention. Seven patients (87.5\%) had an anterior cervical fusion and discectomy, one received a posterior decompression, and three of them also received a corpectomy. After treatment, eight patients $(50 \%)$ had full neurological recovery, independent ambulation and/or no sphincter disturbance. Lastly, two patients (12.5\%) had a negative outcome: minimal recovery, assisted ambulation, paraplegia and/or possible sphincter disturbance. Lastly two patients (12.5\%) expired and the remaining four (25\%) were lost to follow-up (see Table 2), including 2 sent to a skilled nursing facility.

A comparison of patients receiving surgical vs medical management is presented in Table 3. Patients receiving surgery were younger (54.3 vs 61.5 years) and more likely to be male. There were no differences in the number of patients presenting with focal neurological deficits or having a negative outcome. Length of stay was slightly higher in the medical group, although not significant. A significant result in this comparison is comorbidities: patients receiving surgery had less comorbidities, both overall and cardiovascular ( $P=0.026$ and $P=0.0076$, respectively). In terms of

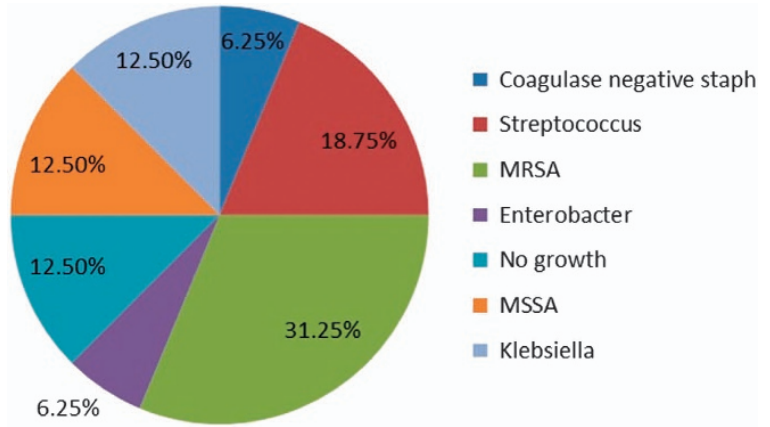

Figure 2. Proportion of different isolated microorganisms in current series of 16 patients diagnosed with CSEA.

isolated pathogenic microorganisms, it was quite similar between the groups including Staphylococcus and Streptococcus species.

Table 3. Summary of results of medical vs surgical treatment

\begin{tabular}{lccc}
\hline & $\begin{array}{c}\text { Medical } \\
(\mathrm{N}=8)\end{array}$ & $\begin{array}{c}\text { Surgical } \\
(\mathrm{N}=8)\end{array}$ & P-value \\
\hline Average age (years) & 61.5 & 54.3 & 0.35 \\
Gender (M) & $25 \% \mathrm{M}$ & $62.5 \% \mathrm{M}$ & $\mathrm{NS}$ \\
Average LOS (days) & 9.38 & 8.25 & 0.79 \\
Focal deficits on presentation & 0 & 4 & $\mathrm{NS}$ \\
& & & \\
Comorbidities (average/patient) & 3.63 & 1.38 & 0.026 \\
All & 4.38 & 1.63 & 0.0076 \\
$\quad$ Cardiovascular & $25 \%$ & $25 \%$ & - \\
Risk of death/negative & \multicolumn{3}{c}{ MRSA (2) } \\
outcome (\%) & MRSA (3) & MSSA & Klebsiella (2) \\
Microorganisms & MSSA & \\
& Staph+Strep & MSSA & \\
\hline
\end{tabular}

Abbreviations: LOS, length of stay; MRSA, methicillin-resistant Staphylococcus aureus; MSSA, methicillin-sensitive Staphylococcus aureus; NS, not significant. ${ }^{\text {a } C a r d i o v a s c u l a r ~ i n c l u d i n g: ~ c o n g e s t i v e ~ h e a r t ~ f a i l u r e, ~ a t r i a l ~}$ fibrillation, hypertension, myocardial infarction, thrombosis, etc.

Literature review

The following is a summary of previous case series $^{2-7,9-12,14,18,20}$. Age of patients diagnosed with CSEA have ranged between 18 and 88 years. The upper cervical spine is less likely afflicted when compared with lower cervical levels; $~ 11 \%$ are between $\mathrm{C} 1$ and $\mathrm{C} 3,56 \%$ between $\mathrm{C} 4$ and $\mathrm{C} 6$ and 33\% between $\mathrm{C} 6$ and T1. Additionally, ventral predisposition is more likely. Most common comorbidities included intravenous drug 
abuse, diabetes mellitus, liver disease and infection elsewhere. Other risk factors were renal disease and dialysis, tobaccoism, cardiovascular, recent dental work and immunosuppression. Previous reported cases had $S$. aureus including methicillinresistant S. aureus and methicillin-sensitive S. aureus, and Streptococcus as the most common infectious microorganisms. Pseudomonas and Brucella were reportedly recovered in others. Patients were treated with either a combination of antibiotics and surgery or with solely medical management. A myriad of surgical approaches and techniques were used including anterior and posterior access procedures, various sorts of fusion methods and conventional operations with discectomy, laminectomy and corpectomy. Neurological recovery and outcome is variable with a seemingly equal distribution among those making full improvement vs those with unchanged symptomatology following treatment and/or without resolution of deficits.

\section{DISCUSSION}

Spinal epidural abscess occurring in the cervical region holds a peculiar degree of interest. In the literature, case series involving SEA of the cervical region show several important trends with regards to demographic factors, spinal level involvement, treatment modalities and complications. Clinical manifestations of patients with CSEA include the classic diagnostic triad of fever, spinal pain and neurological deficits. Fever is a common finding in our analysis (31.25\%), although not the most common on presentation. Neurological symptoms spanned from sphincter incontinence to localized paresthesias and back pain, myalgias, monoparesis, ascending paraparesis, paraplegia and quadraparesis. $^{2,4,6,7,10,13}$ In fact, spinal pain and focal neurological findings accounted for the highest percentage of symptomology in our patient population (62.5\%). Focal neurological findings were further stratified into either paralysis/paresis $(43.75 \%)$ or paresthesias/pain (18.75\%).

While the general age group of CSEA is reportedly between 50 and 70 years of age, Walters et al. ${ }^{10}$ documented CSEA in patients as young as 18 years. However, it should be noted that this patient had CSEA originating from Pseudomonas aeruginosa following a dental extraction. In general, pathogenic seeding is either via extension from infected tissue or by direct inoculation following spine surgery or intervention. ${ }^{8}$ With regards to exact levels of involvement, it has been noted previously that C4-C5 and C5-C6 are most likely affected, with the ventral aspect of the spine being most common. ${ }^{2,3,7,13}$ Results from our analysis also showed that more distal cervical levels (C5-C7) were most commonly involved $(68.75 \%)$. Reasons for this phenomenon are not quite clear and can be attributed to anatomy-less protection and coverage of the lower cervical spine, structures in its close proximity and a possible increased likelihood of injury and degenerative joint disease.

Commonly associated comorbidities in CSEA patients include ischemic heart disease, diabetes, renal failure, alcoholic liver cirrhosis, viral hepatitis, immunosuppressive therapy, and malignancy. $3,4,7,13$ Vascular disease accounted for the most commonly associated comorbidity in our series (56.25\% patients) with malignancy and chronic inflammatory disease accounting for the least common (12.5\% patients each). When comparing those with a better outcome to those with a poorer outcome (Table 2), on average both groups had the same number of comorbidities ( 3.7 comorbidities per patient). On the other hand, when comparing specific comorbidities, the group with worse outcomes does have more cardiovascular comorbidities such as ischemic heart disease, heart failure and deep vein thrombosis (on average, 3 vs 1 cardiovascular comorbidities/patient). Finally, of note, a small number of patients had a previous history of spinal pathology and/or spine surgery in their past that is unrelated to their current spinal infection.
In our series, S. aureus was the primary pathogen, similar to previous publications. ${ }^{3,4,6,7,13-17}$ However, three patients grew Gram-negative bacteria. Others reported Streptococcus and Pseudomonas occurring in a significant percentage of patients. ${ }^{7,9}$ Additionally, Gram-negative bacilli as a cause of SEA in general has shown to be $\sim 16 \%$ of all SEA cases. ${ }^{6,8,17}$ Pina et al. ${ }^{2}$ described CSEA arising secondary to Brucella, where the majority of cases originated from animal contact in farmlands and Muzii et al. ${ }^{18}$ documented mycobacterium tuberculosis isolated in two epidural cervical abscess cases, both of which were immunocompromised due to an extensive history of intravenous drug use. In terms of imaging, magnetic resonance imaging of the cervical spine is the study of choice for diagnosis of CSEA (Figure 1). ${ }^{8}$ Pre- and postcontrast magnetic resonance imaging are important for surgical planning and to evaluate the extent of involvement and extension into the adjacent space. ${ }^{8,13}$

In general, patients undergo both medical and surgical treatment options. The majority of patients reported in the literature were started empirically on broad spectrum intravenous antibiotics at presentation. Postoperative antibiotic therapy was also administered for variable durations spanning from 2-3 months. ${ }^{2,5}$ In other studies, patients were not offered antibiotics until after surgical evacuation and the causative organism was identified, particularly if the patient was not septic on presentation. For example, in Ghobrial et al.'s study ${ }^{12}$ any patient presenting with CSEA underwent immediate surgery whether they had neurological sequelae or not. On the other hand, patients receiving solely medical treatment were more likely to have significantly better motor scores at the time of presentation. ${ }^{10}$ Similarly, in terms of the choice of treatment modality offered to our patients (half receiving antibiotics as the only treatment), we found that although surgery combined with systemic antibiotics was the treatment of choice for most patients, there are a subset of patients where exclusive medical therapy may suffice. Generally, patients without cord involvement and/or focal neurological deficits as well as those with resolution of the infection at follow-up were deemed appropriate candidates for antibiotic therapy alone.

As seen in the patients presenting to our hospital, the complication rates and outcomes of CSEA can range from total symptom resolution to death. Full recovery including the ability to ambulate independently without residual sphincter disturbance was seen in half the patients. By and large, the degree of neurologic recovery after surgery is related to the duration of the neurologic deficit. ${ }^{7}$ A delay in diagnosis also increases the risk of neurological dysfunction due to spinal cord ischemia or nerve compression. ${ }^{18}$ In another series, $\sim 50 \%$ demonstrated neurological improvement following surgery, and one had evidence of worsening motor scores, while the rest were stable. $^{12}$ Seven patients in Shousha et al's study (58.3\%) showed considerable neurological improvement after treatment and the other $5(41.7 \%)$ remained without improvement. Other studies demonstrated post-treatment interventions such as aggressive rehabilitation and physical therapy to contribute towards moderate improvement in motor functioning. ${ }^{19}$

The decision to operate on patients with CSEA is made on a case-by-case evaluation of each of the patients along with assessment of other determinants of a positive outcome. Those with overly severe disease, neurological deficits, life-threatening symptoms and lack of infection clearance at follow-up should receive surgery. An operation may also be offered to those with mild to moderate disease with a consideration of factors such as timing of presentation, severity of symptoms and the surgical risk of the patient. The plan for surgery, while left up to the spine surgeon's discretion, is usually undertaken along with recommendations from colleagues in other disciplines (general medicine and infectious disease services). 
Our study is limited by a number of factors including data, a retrospective small number of patients and missing long-term follow-up. Overall, there has been few series on CSEA published in the literature and most are case reports. ${ }^{20-31}$ We suggest multicenter, prospective studies in the future along with longterm follow-up and outcomes data.

\section{CONCLUSION}

CSEA should be suspected in those with pertinent risk factors and treated immediately. Surgical intervention is often used, although some patients may be treated primarily with medical management. Prognosis is dependent on factors such as the timing and neurological condition at presentation, extent of spinal canal involvement and promptness of surgery. Future large, prospective studies with complete follow-up are recommended.

\section{COMPETING INTERESTS}

The authors declare no conflict of interest.

\section{REFERENCES}

1 Gellin BG, Weingarten K, Gamache FW Jr, Hartman B.J. Epidural abscess. In: Scheld WM, Whitley RJ, Durack DT (eds) Infections of the Central Nervous System, 2nd edn. Lippincott-Raven Publishers: Philadelphia, PA, USA, 1997, p 507.

2 Pina MA, Modrego PJ, Uroz JJ, Cobeta JC, Lerin FJ, Baiges JJ. Brucellar spinal epidural abscess of cervical location: report of four cases. Eur Neurol 2001; 45: 249-253.

3 Faruqui S, Palacios E, Friedlander P, Melgar M, Alvernia J, Parry PV. Nontraumatic retropharyngeal abscess complicated by cervical osteomyelitis and epidural abscess in post-Katrina New Orleans: four cases. J Ear Nose Throat 2009; 88: E14.

4 Gezici A, Ergün R. Cervical epidural abscess in haemodialysis patients by catheter related infection: report of two cases. J Korean Med Sci 2010; 25: 176-179.

5 Kricun R, Shoemaker E, Chovanes G, Stephens HW. Epidural abscess of the cervical spine: MR findings in five cases. American Journal of Roentgenology 1992; 158: $1145-1149$.

6 Liou LM, Shih PY. Epidural abscess of the cervical spine with atypical manifestations: a report of two cases. Neurologist 2007; 13: 215-218.

7 Shousha M, Boehm H. Surgical treatment of cervical spondylodiscitis: a review of 30 consecutive patients. Spine 2012; 37: 30-36.

8 Giuffrida S, Chiaramonte I, Saponara R, Greco S, Giammona G, Nicoletti G et al. Cervical epidural abscess: serial MRI study. J Neurosurg Sci 1997; 41: 219-223.

9 Walters H, Measley R. Two cases of Pseudomonas aeruginosa epidural abscesses and cervical osteomyelitis after dental extractions. Spine 2008; 33: 293-296.

10 Alton TB, Patel AR, Bransford RJ, Bellabarba C, Lee MJ, Chapman JR. Is there a difference in neurologic outcome in medical versus early operative management of cervical epidural abscesses? Spine J 2015; 15: 10-17.

11 Shousha M, Heyde C, Boehm H. Cervical spondylodiscitis: change in clinical picture and operative management during the last two decades. A series of 50 patients and review of literature. Eur Spine J 2015; 24: 571-576.
12 Ghobrial GM, Viereck MJ, Margiotta PJ, Beygi S, Maulucci CM, Heller JE et al. Surgical management in 40 consecutive patients with cervical spinal epidural abscesses: shifting toward circumferential treatment. Spine (Phila Pa 1976) 2015; 40: E949-E953.

13 Piccolo R, Passanisi M, Chiaramonte I, Tropea R, Mancuso P. Cervical spinal epidural abscesses. A report on five cases. J Neurosurg Sci 1999; 43: 63.

14 Muffoletto A, Nader R, Westmark R, Nauta HJ, Garges KJ, Hadjipavlou AG. Hematogenous pyogenic facet joint infection of the subaxial cervical spine: a report of two cases and review of the literature. $J$ Neurosurg 2001; 95: 135-138.

15 Pöpping DM, Zahn PK, Van Aken HK, Dasch B, Boche R, Pogatzki-Zahn EM. Effectiveness and safety of postoperative pain management: a survey of 18925 consecutive patients between 1998 and 2006 (2nd revision): a database analysis of prospectively raised data. Br J Anesth 2008; 101: 832-840.

16 Sendi $P$, Bregenzer T, Zimmerli W. Spinal epidural abscess in clinical practice. $Q \mathrm{~J}$ Med 2008; 101: 1-12.

17 Nussbaum E, Rigamonti D, Standiford H, Numaguchi Y, Wolf AL, Robinson WL. Spinal epidural abscess: a report of 40 cases and review. Surg Neurol 1992; 38: 225.

18 Muzii VF, Mariottini A, Zalaffi A, Carangelo BR, Palma L. Cervical spine epidural abscess: experience with microsurgical treatment in eight cases. J Neurosurg Spine 2006; 5: 392-397.

19 Siddiq F, Chowfin A, Tight R, Sahmoun AE, Smego RA Jr. Medical vs surgical management of spinal epidural abscess. Arch Intern Med 2004; 164: 2409-2412.

20 Ecki M, Özbek Z, Gökoğlu A, Menkü A. Surgical management of cervical spinal epidural abscess caused by Brucella melitensis: report of two cases and review of the literature. J Korean Neurosurg 2012; 51: 383-387.

21 Sørensen P. Spinal epidural abscesses: conservative treatment for selected subgroups of patients. Br J Neurosurg 2003; 17: 513-518.

22 Cook TM, Counsell D, Wildsmith JA. Major complications of central neuraxial block: report on the third National Audit Project of the Royal College of Anaesthetists. Br J Anesth 2009; 102: 179.

23 Reynolds F. Neurological infections after neuraxial anesthesia. Anesthesiol Clin 2008; 26: 23.

24 Sethna NF, Clendenin D, Athiraman U, Solodiuk J, Rodriguez DP, Zurakowski D. Incidence of epidural catheter-associated infections after continuous epidural analgesia in children. Anesthesiology 2010; 113: 224-232.

25 Gaul C, Neundörfer B, Winterholler M. latrogenic (para-) spinal abscesses and meningitis following injection therapy for low back pain. Pain 2005; 116: 407.

26 Akalan N, Ozgen T. Infection as a cause of spinal cord compression: a review of 36 spinal epidural abscess cases. Acta Neurochirurg 2000; 142: 17.

27 Danner R, Hartman B. Update on spinal epidural abscess: 35 cases and review of the literature. Rev Infect Dis 1987; 9: 265

28 Darouiche R, Hamill R, Greenberg S, Weathers SW, Musher DM. Bacterial spinal epidural abscess. Review of 43 cases and literature survey. Medicine 1992; 71: 369 .

29 Rigamonti D, Liem L, Wolf AL, Fiandaca MS, Numaguchi Y, Hsu FP et al. Epidural abscess in the cervical spine. Mt Sinai J Med 1994; 61: 357.

30 Davis D, Wold R, Patel R, Tran AJ, Tokhi RN, Chan TC et al. The clinical presentation and impact of diagnostic delays on emergency department patients with spinal epidural abscess. J Emerg Med 2004; 26: 285.

31 Koo DW, Townson AF, Dvorak MF, Fisher CG. Spinal epidural abscess: a 5-year case-controlled review of neurologic outcomes after rehabilitation. Arch Phys Med Rehabil 2009; 90: 512. 